\title{
Erratum to: Exact expression of the density of the sample generalized variance and applications
}

\author{
T. Pham-Gia $\cdot$ N. Turkkan
}

Published online: 10 March 2010

(C) Springer-Verlag 2010

\section{Erratum to: Stat Papers \\ DOI 10.1007/s00362-008-0187-3}

To reduce the variation interval of $x$ in Fig. 1, the scaling factor $k=1.6 \times 10^{-4}$ has been introduced. Multiplying the interval $(544.22,66076.98)$ by $k$, we have the interval $(0.0870,10.57)$ which contains the value of $\left|\Sigma_{1}\right|=0.6645$, as expected.

The online version of the original article can be found under doi:10.1007/s00362-008-0187-3.

T. Pham-Gia $(\bowtie) \cdot$ N. Turkkan

Universite de Moncton, Moncton, Canada

e-mail:phamgit@umoncton.ca 